\title{
Antiresorptive Drugs Beyond Bisphosphonates and Selective Oestrogen Receptor Modulators for the Management of Postmenopausal Osteoporosis
}

\author{
J. Y. Reginster $\cdot$ A. Neuprez $\cdot$ C. Beaudart $\cdot$ \\ M. P. Lecart $\cdot$ N. Sarlet $\cdot$ D. Bernard $\cdot$ \\ S. Disteche $\cdot$ O. Bruyere
}

Published online: 6 May 2014

(c) The Author(s) 2014. This article is published with open access at Springerlink.com

\begin{abstract}
Osteoporotic fractures are a major cause of morbidity in the elderly population. Since postmenopausal osteoporosis is related to an increase in osteoclastic activity at the time of menopause, inhibitors of bone resorption have genuinely been considered an adequate strategy for prevention and treatment of osteoporosis. Bisphosphonates and selective oestrogen receptor modulators are widely prescribed to treat osteoporosis. However, other antiresorptive drugs have been developed for the management of osteoporosis, with the objective of providing a substantial reduction in osteoporotic fractures at all skeletal sites, combined with an acceptable long-term skeletal and systemic safety profile. Denosumab, a human monoclonal antibody to receptor activator for nuclear factor kappa B ligand, has shown efficacy against vertebral, nonvertebral and hip fractures. Its administration every 6 months as a subcutaneous formulation might significantly influence compliance and persistence to therapy. Additional results regarding long-term skeletal safety (i.e. osteonecrosis of the jaw and atypical diaphyseal femoral fracture) are needed. Odanacatib, a selective cathepsin $\mathrm{K}$ inhibitor, is a promising new approach to the inhibition of osteoclastic resorption, with the potential to uncouple bone formation from bone resorption. Results regarding its anti-fracture efficacy are expected in the coming months.
\end{abstract}

J. Y. Reginster $(\bowtie) \cdot$ A. Neuprez $\cdot$ C. Beaudart .

M. P. Lecart - N. Sarlet - D. Bernard - S. Disteche - O. Bruyere Department of Public Health, Epidemiology and Health

Economics, CHU Sart Tilman, University of Liège, 4020 Liège, Belgium

e-mail: jyreginster@ulg.ac.be

J. Y. Reginster · A. Neuprez - C. Beaudart .

M. P. Lecart · N. Sarlet · D. Bernard - S. Disteche - O. Bruyere

Bone and Cartilage Metabolism Unit, CHU Centre Ville,

University of Liège, Liège, Belgium

\section{Introduction}

Osteoporosis is defined as a systemic skeletal disease characterized by low bone mass and microarchitectural deterioration of bone tissue, with a consequent increase in bone fragility and susceptibility to fractures [1]. Osteoporotic fractures are a major cause of morbidity in the population [2]. Approximately $50 \%$ of fracture-related deaths in women are due to hip fractures, $28 \%$ to clinical vertebral fractures and $22 \%$ to other factures. Since postmenopausal osteoporosis was originally related to an increase in osteoclastic activity at the time of menopause, because of the disappearance of the oestrogen inhibitory effect on bone resorption, inhibitors of bone resorption have genuinely been considered an adequate strategy for prevention and treatment of osteoporosis. Bisphosphonates have been widely prescribed to postmenopausal women for treatment and prevention of osteoporosis [3]. However, given a background of reports of recent safety problems [4-6] and questions about optimal duration of use, substantial declines in prescriptions and sales of oral bisphosphonates (since 2007-2008) and intravenous bisphosphonates (since 2010) for osteoporosis treatment have been observed [3]. Furthermore, it has been suggested that more than half of the potential clinical benefits of oral bisphosphonates in patients with osteoporosis are lost because of poor adherence to treatment $[6,7]$. Selective oestrogen receptor modulators have been shown to significantly reduce the risk of vertebral fracture [8], but their effects on nonvertebral fractures were only shown in post hoc analysis conducted in women with severe vertebral fracture at baseline $[8,9]$. This lack of efficacy against nonvertebral fractures in the overall osteoporotic population, combined with a significant increase in venous thromboembolic events, has limited their use in terms of first-line treatment 
of osteoporosis, particularly in elderly women [10]. A substantial body of evidence indicates that many generic formulations of oral bisphosphonates are less well tolerated than the proprietary preparations, which results in significantly poorer adherence and thus effectiveness [11]. Other antiresorptive drugs have been developed for the management of osteoporosis, with the objective of providing substantial reductions in osteoporotic fractures at all skeletal sites, combined with an acceptable long-term skeletal and systemic safety profile. Particular emphasis has been put on interventions that might improve long-term adherence to therapy.

\section{Denosumab (Human Monoclonal Antibody to Receptor Activator for Nuclear Factor Kappa B Ligand)}

\subsection{Mode of Action}

Receptor activator for nuclear factor kappa B ligand (RANKL), a member of the tumour necrosis factor superfamily, is expressed by osteoblasts and their immature precursors and is necessary and sufficient for osteoclastogenesis. RANKL activates its receptor, RANK, which is expressed on osteoclasts and their precursors, thus promoting osteoclast formation and activation and prolonging osteoclast survival by suppressing apoptosis [12]. In vivo, the effects of RANKL are counteracted by osteoprotegerin, a soluble neutralizing decoy receptor. Elderly women with hip fractures exhibit increased RANKL/osteoprotegerin messenger RNA content in the iliac bone [13].

\subsection{Phase 1 Studies}

Denosumab, a fully human monoclonal antibody to RANKL, blocks binding of RANKL to RANK. In healthy postmenopausal women, a single subcutaneous dose of denosumab resulted in a dose-dependent, rapid (within $12 \mathrm{~h}$ ), profound $(\leq 84 \%)$ and sustained ( $\leq 6$ months) decrease in urinary crosslinked N-telopeptides of type I collagen (NTx). At 6 months, there was a mean change from baseline of $-81 \%$ in the $3.0 \mathrm{mg} / \mathrm{kg}$ denosumab group compared with $-10 \%$ in the placebo group. Bonespecific alkaline phosphatase levels did not decrease remarkably until after 1 month, indicating that the effect of denosumab is primarily antiresorptive. No related serious adverse events occurred [14].

\subsection{Phase 2 Studies}

The efficacy and safety of subcutaneously administered denosumab were evaluated over a period of 24 months in
412 postmenopausal women with low bone mineral density (BMD) (a $T$ score of -1.8 to -4.0 at the lumbar spine or -1.8 to -3.5 at the proximal femur). Subjects were randomly assigned to receive either denosumab every 3 months (at a dose of 6,14 or $30 \mathrm{mg}$ ), denosumab every 6 months (at a dose of 14, 60, 100 or $210 \mathrm{mg}$ ), open-label oral alendronate once weekly (at a dose of $70 \mathrm{mg}$ ) or placebo. The primary endpoint was the percentage change from baseline in BMD at the lumbar spine at 12 months. Changes in bone turnover were assessed by measurement of serum and urine telopeptides and bone-specific alkaline phosphatase. Denosumab treatment for 12 months resulted in increases in BMD of 3.0-6.7 \% at the lumbar spine (as compared with an increase of $4.6 \%$ with alendronate and a loss of $0.8 \%$ with placebo), $1.9-3.6 \%$ at the total hip (as compared with an increase of $2.1 \%$ with alendronate and a loss of $0.6 \%$ with placebo) and $0.4-1.3 \%$ at the distal third of the radius (as compared with decreases of $0.5 \%$ with alendronate and $2.0 \%$ with placebo). It is worth noting that increases in BMD at the distal radius have not been described with bisphosphonates. Near-maximal reductions in the mean levels of serum C-telopeptide (CTX) from baseline were evident 3 days after the administration of denosumab. The duration of the suppression of bone turnover appeared to be dose dependent [15].

After 24 months, patients receiving denosumab either continued treatment at $60 \mathrm{mg}$ every 6 months for an additional 24 months, discontinued therapy or discontinued treatment for 12 months then re-initiated denosumab (60 mg every 6 months) for 12 months. The placebo cohort was maintained. Alendronate-treated patients discontinued alendronate and were followed [16]. Changes in BMD and bone turnover markers (BTMs), as well as safety outcomes, were evaluated. Overall, 262 of 412 patients (64\%) completed 48 months of the study. Continuous, long-term denosumab treatment increased BMD at the lumbar spine (by 9.4-11.8 \%) and total hip (by 4.0-6.1\%). BTMs were consistently suppressed over 48 months. Discontinuation of denosumab was associated with a BMD decrease of $6.6 \%$ at the lumbar spine and $5.3 \%$ at the total hip within the first 12 months of treatment discontinuation. Retreatment with denosumab increased lumbar spine BMD by $9.0 \%$ from the original baseline values. BTM levels increased upon discontinuation and decreased with retreatment. Adverse event rates were similar among treatment groups [17]. The study was then extended for 4 years, where all subjects received denosumab. Of the 262 subjects who completed the parent study, 200 enrolled in the extension and, of these, 138 completed the extension. For the subjects who received 8 years of continued denosumab treatment, BMD at the lumbar spine $(N=88)$ and total hip $(N=87)$ increased by 16.5 and $6.8 \%$, respectively, 
compared with their parent study baseline values, and by 5.7 and $1.8 \%$, respectively, compared with their extension study baseline values. For the 12 subjects in the original placebo group, 4 years of denosumab resulted in BMD gains comparable to those observed during the 4 years of denosumab in the parent study. Reductions in BTMs were sustained over the course of continued denosumab treatment. Reductions were also observed when the placebo group transitioned to denosumab. The adverse event profile was consistent with those in previous reports and an aging cohort [16].

In 332 postmenopausal women with lumbar spine BMD $T$ scores between -1.0 and -2.5 who were randomly assigned to receive either denosumab $60 \mathrm{mg}$ or placebo subcutaneously every 6 months, denosumab significantly increased lumbar spine BMD, compared with placebo, at 24 months $(6.5$ versus $-0.6 \%, P<0.0001)$. Denosumab also produced significant increases in BMD at the total hip, one third radius and total body $(P<0.0001$ versus placebo); increased distal radius volumetric BMD $(P<0.01)$; improved hip structural analysis parameters; and significantly suppressed serum CTX, tartrate-resistant acid phosphatase-5b and intact $\mathrm{N}$-terminal propeptide of type 1 procollagen [18].

\subsection{Phase 3 Studies}

In a phase 3 , multicentre, double-blind study comparing the efficacy and safety of denosumab with alendronate in postmenopausal women with low bone mass, 1,189 postmenopausal women with a $T$ score $\leq-2.0$ at the lumbar spine or total hip were randomized 1:1 to receive subcutaneous denosumab injections (60 mg every 6 months) plus oral placebo weekly $(n=594)$ or oral alendronate weekly $(70 \mathrm{mg}$ ) plus subcutaneous placebo injections every 6 months $(n=595)$. Changes in BMD were assessed at the total hip, femoral neck, trochanter, lumbar spine and one third radius at 6 and 12 months, and in BTMs at months 1, 3, 6, 9 and 12. Safety was evaluated by monitoring of adverse events and laboratory values. At the total hip, denosumab significantly increased BMD, compared with alendronate at month 12 (3.5 versus $2.6 \%$, $P<0.0001)$. Furthermore, significantly greater increases in BMD were observed with denosumab treatment at all measured skeletal sites (12-month treatment difference: $0.6 \%$ at the femoral neck, $1.0 \%$ at the trochanter, $1.1 \%$ at the lumbar spine, $0.6 \%$ at the one third radius; $P \leq 0.0002$ at all sites). Denosumab treatment led to a significantly greater reduction in BTMs than alendronate therapy. Adverse events and laboratory values were similar for denosumab- and alendronate-treated subjects. Denosumab demonstrated significantly larger gains in BMD and greater reduction in BTMs than alendronate. The overall safety profile was similar for both treatments [19].
In the FREEDOM (Fracture Reduction Evaluation of Denosumab in Osteoporosis Every 6 Months) study, 7,868 women between the ages of 60 and 90 years who had a BMD $T$ score of less than -2.5 but not less than -4.0 at the lumbar spine or total hip were randomly assigned to receive either $60 \mathrm{mg}$ of denosumab or placebo subcutaneously every 6 months for 36 months. The primary endpoint was new vertebral fracture. Secondary endpoints included nonvertebral and hip fractures.

As compared with placebo, denosumab reduced the risk of new radiographic vertebral fracture, with a cumulative incidence of $2.3 \%$ in the denosumab group versus $7.2 \%$ in the placebo group (risk ratio $0.32,95 \%$ confidence interval [CI] $0.26-0.41, P<0.001$ ), a relative decrease of $68 \%$. Denosumab reduced the risk of hip fracture, with a cumulative incidence of $0.7 \%$ in the denosumab group versus $1.2 \%$ in the placebo group (hazard ratio $0.60,95 \% \mathrm{CI}$ $0.37-0.97, P=0.04$ ), a relative decrease of $40 \%$. Denosumab also reduced the risk of nonvertebral fracture, with a cumulative incidence of $6.5 \%$ in the denosumab group versus $8.0 \%$ in the placebo group (hazard ratio $0.80,95 \%$ CI $0.67-0.95, P=0.01$ ), a relative decrease of $20 \%$. There was no increase in the risk of cancer, infection, cardiovascular disease, delayed fracture healing or hypocalcaemia, and there were no cases of osteonecrosis of the jaw and no adverse reactions to the injection of denosumab [20].

Participants who completed the FREEDOM trial were eligible to enter an extension to continue the evaluation of denosumab efficacy and safety for up to 10 years. For the 5 -year extension results, women from the FREEDOM denosumab group had two more years of denosumab treatment (the long-term group) and those from the FREEDOM placebo group had 2 years of denosumab exposure (the crossover group). A total of 4,550 women were enrolled in the extension (2,343 long-term; 2,207 crossover). Reductions in BTMs were maintained (in the long-term group) or occurred rapidly (in the crossover group) following denosumab administration. In the long-term group, lumbar spine and total hip BMD increased further, resulting in 5-year gains of 13.7 and $7.0 \%$, respectively. In the crossover group, BMD increased at the lumbar spine (7.7 \%) and total hip (4.0\%) during the 2-year denosumab treatment. Yearly fracture incidences for both groups were below the rates observed in the FREEDOM placebo group and below the rates projected for a 'virtual untreated twin' cohort. Adverse events did not increase with long-term denosumab administration. Two adverse events in the crossover group were adjudicated as being consistent with osteonecrosis of the jaw. The authors concluded that 5-year denosumab treatment in women with postmenopausal osteoporosis maintained BTM reduction and increased $\mathrm{BMD}$, and was associated with low fracture rates and a favourable risk/benefit profile [21]. 
Women from the FREEDOM denosumab group received three more years of denosumab for a total of 6 years (in the long-term group), and women from the FREEDOM placebo group received 3 years of denosumab (in the crossover group). In the long-term group, BMD further increased for cumulative 6-year gains of $15.2 \%$ (lumbar spine) and $7.5 \%$ (total hip). During the first 3 years of denosumab treatment, the crossover group had significant gains in lumbar spine BMD (9.4\%) and total hip BMD (4.8\%), similar to the findings in the long-term group during the 3-year FREEDOM trial. In the long-term group, fracture incidences remained low and below the rates projected for a virtual placebo cohort. In the crossover group, the 3-year incidences of new vertebral and nonvertebral fractures were similar to those of the FREEDOM denosumab group. Incidence rates of adverse events did not increase over time. Six participants had events of osteonecrosis of the jaw confirmed by adjudication. One participant had a fracture adjudicated as being consistent with an atypical femoral fracture. The authors concluded that denosumab treatment for 6 years remained well tolerated, maintained reduced bone turnover and continued to increase BMD. The fracture incidence remained low [22].

To understand the differences in the fracture incidence between treatment groups after cessation of the investigational product, subjects in FREEDOM who discontinued treatment after receiving 2-5 doses of denosumab or placebo and who continued study participation for $\geq 7$ months were evaluated. The off-treatment observation period for each individual subject began 7 months after the last dose and lasted until the end of the study. This subgroup of 797 subjects (470 placebo, 327 denosumab), who were evaluable during the off-treatment period, showed similar baseline characteristics for age, prevalent fracture, and lumbar spine and total hip BMD $T$ scores. During treatment, more placebo-treated subjects than denosumabtreated subjects sustained a fracture and had significant decreases in BMD. During the off-treatment period (median 0.8 years per subject), 42 versus $28 \%$ of placebo- and denosumab-treated subjects, respectively, initiated other therapy. Following discontinuation, similar percentages of subjects in both groups sustained a new fracture (9\% placebo, $7 \%$ denosumab), resulting in a fracture rate per 100 subject-years of 13.5 for placebo and 9.7 for denosumab (hazard ratio 0.82, $95 \%$ CI 0.49-1.38), adjusted for age and total hip BMD $T$ score at baseline. There was no apparent difference in the fracture occurrence pattern between the groups during the off-treatment period [23].

The BTM substudy of the FREEDOM trial included 160 women randomized to receive subcutaneous denosumab (60 mg) or placebo injections every 6 months for 3 years. Biochemical markers of bone resorption (serum CTX and tartrate-resistant acid phosphatase) and bone formation (serum procollagen type I N-propeptide and bone-specific alkaline phosphatase) were measured at baseline and at 1 , 6, 12, 24 and 36 months. The decreases in CTX were more rapid and greater than the decreases in procollagen type I $\mathrm{N}$-propeptide and bone-specific alkaline phosphatase. One month post-injection, CTX levels in all denosumab-treated subjects decreased to levels below the premenopausal reference interval. CTX values at the end of the dosing period were influenced by baseline CTX values and the dosing interval. The percentage of subjects with CTX levels below the premenopausal reference interval before each subsequent injection decreased from 79 to $51 \%$ during the study. CTX and procollagen type I N-propeptide remained below the premenopausal reference interval at all timepoints in 46 and $31 \%$ of denosumab-treated subjects, respectively. With denosumab, but not with placebo, there were significant correlations between CTX reduction and the BMD increase ( $r$ value -0.24 to -0.44 ) [24].

The primary data from the phase 3 FREEDOM study of the effects of denosumab in women with postmenopausal osteoporosis were used to compute country-specific probabilities, using the FRAX tool (version 3.2). At baseline, the median 10-year probability of a major osteoporotic fracture (with BMD) was approximately $15 \%$, and for hip fracture, the risk was approximately $5 \%$, in both groups. In the simplest model adjusted for age and fracture probability, treatment with denosumab over 3 years was associated with a $32 \%$ (95 \% CI 20-42\%) decrease in clinical osteoporotic fractures. Denosumab reduced the fracture risk to a greater extent in those at moderate to high risk. For example, at $10 \%$ probability, denosumab decreased the fracture risk by $11 \%$ $(P=0.629)$, whereas at $30 \%$ probability (the 90 th percentile of the study population), the reduction was $50 \%$ $(P=0.001)$. The reduction in fracture was independent of prior fracture, a parental history of hip fracture or secondary causes of osteoporosis. A low body mass index was associated with greater efficacy. Overall, the efficacy of denosumab was greater in those at moderate to high risk of fracture, as assessed by FRAX [25].

Because of the large number of patients included in the FREEDOM study and the wide scatter in age (60-90 years), subgroup analyses were prospectively planned before study unblinding to evaluate the effect of denosumab on new vertebral and nonvertebral fractures across various subgroups. The anti-fracture efficacy of denosumab did not significantly differ for any of the subgroups that were analyzed, including patients above the age of 75 years [26].

\subsection{Supportive Studies}

A multicentre, international, randomized, double-blind, double-dummy study was conducted in 504 
postmenopausal women $\geq 55$ years of age with a BMD $T$ score of -2.0 and -4.0 who had been receiving alendronate therapy for at least 6 months (in the STAND study). Subjects received open-label branded alendronate $70 \mathrm{mg}$ once weekly for 1 month and then were randomly assigned to either continued weekly alendronate therapy or subcutaneous denosumab $60 \mathrm{mg}$ every 6 months, and were followed for 12 months. Changes in BMD and BTMs were evaluated. In subjects transitioning to denosumab, total hip BMD increased by $1.90 \%$ at month 12 , compared with a $1.05 \%$ increase in subjects continuing on alendronate $(P<0.0001)$. Significantly greater BMD gains with denosumab than with alendronate were also achieved at 12 months at the lumbar spine, femoral neck and one third radius (all $P<0.0125$ ). Median serum CTX levels remained near baseline in the alendronate group and were significantly decreased with denosumab versus alendronate $(P<0.0001)$ at all timepoints [27].

Another trial was designed to compare the efficacy and safety of denosumab with risedronate over 12 months in postmenopausal women who transitioned from daily or weekly alendronate treatment and were considered to be suboptimally adherent to therapy. In this randomized, open-label study, postmenopausal women aged $\geq 55$ years received denosumab $60 \mathrm{mg}$ subcutaneously every 6 months or risedronate $150 \mathrm{mg}$ orally every month for 12 months. The endpoints included the percentage changes from baseline in total hip BMD (the primary endpoint), femoral neck BMD and lumbar spine BMD at month 12; and the percentage changes from baseline in CTX at months 1 and 6. Safety was also assessed. A total of 870 subjects were randomized (435 to risedronate, 435 to denosumab), who had a mean age of 67.7 (standard deviation [SD] 6.9) years; mean BMD $T$ scores of $-1.6(0.9),-1.9$ (0.7) and $-2.2(1.2)$ at the total hip, femoral neck and lumbar spine, respectively; and median CTX of $0.3 \mathrm{ng} / \mathrm{mL}$ at baseline. At month 12, denosumab significantly increased BMD compared with risedronate at the total hip (2.0 versus $0.5 \%)$, femoral neck $(1.4$ versus $0 \%)$ and lumbar spine (3.4 versus $1.1 \%, P=0.0001$ at all sites). Denosumab significantly decreased CTX, compared with risedronate, at month 1 (a median change from baseline of -78 versus $-17 \%, P<0.0001)$ and at month $6(-61$ versus $-23 \%, P<0.0001)$. Overall and serious adverse events were similar between groups. The authors concluded that in postmenopausal women who were suboptimally adherent to alendronate therapy, transitioning to denosumab was well tolerated and more effective than risedronate in increasing BMD and reducing bone turnover [28].

Iliac crest bone biopsies were collected at 24 and/or 36 months from osteoporotic postmenopausal women in the FREEDOM study (45 women receiving placebo and 47 denosumab) and at 12 months from postmenopausal women who had previously been treated with alendronate in the STAND study (21 continuing alendronate and 15 changed to denosumab at trial entry). Qualitative histological evaluation of the biopsies was unremarkable. In the FREEDOM study, the median eroded surface was reduced by more than $80 \%$, and osteoclasts were absent from more than $50 \%$ of biopsies in the denosumab group. Double labelling in trabecular bone was observed in $94 \%$ of placebo bones and in $19 \%$ of those treated with denosumab. The median bone-formation rate was reduced by $97 \%$. Among denosumab-treated subjects, those with double labels and those with absent labels had similar levels of biochemical BTMs. In the STAND trial, indices of bone turnover tended to be lower in the denosumab group than in the alendronate group. Double labelling in trabecular bone was seen in $20 \%$ of the denosumab biopsies and in $90 \%$ of the alendronate samples [29].

Two hundred and fifty women with osteoporosis were randomized to 12 months of treatment with subcutaneous denosumab $60 \mathrm{mg}$ every 6 months or oral alendronate $70 \mathrm{mg}$ once weekly, then crossed over to the other treatment. The frequency of the primary endpoint, treatment adherence at 12 months, was $76.6 \%$ for alendronate and $87.3 \%$ for denosumab [30].

\subsection{Health Economics}

Besides the clinical profile of a new drug, it becomes increasingly important to assess whether the drug represents good value for money. One study aimed to examine the potential cost effectiveness of denosumab in the treatment of postmenopausal osteoporotic women. An updated version of a validated Markov microsimulation model was used to estimate the cost (in 2009 Euro values) per qualityadjusted life-year (QALY) gained of 3-year denosumab treatment compared with no treatment. The model was populated with cost and epidemiological data for Belgium from a healthcare perspective, and the base-case population was defined from the FREEDOM trial. The effect of denosumab after treatment cessation was conservatively assumed to decline linearly over 1 year. Uncertainty was investigated using one-way and probabilistic sensitivity analyses. In particular, additional analyses were performed in populations (aged over 60 years) where osteoporosis medications are currently reimbursed in many European countries, i.e. with a BMD $T$ score $\leq 2.5$ or prevalent vertebral fracture. In the base-case analysis, the cost per QALY gained of denosumab compared with no treatment was estimated at $€ 28,441$. This value decreased to $€ 15,532$ and to $€ 11,603$ for women with a BMD $T$ score of -2.5 or prevalent vertebral fracture, respectively. Additional analyses showed that over the entire age range that was 
examined (60-80 years), the cost effectiveness of denosumab fell below the commonly accepted threshold of $€ 30,000$ per QALY gained for women with a BMD $T$ score $\leq-2.5$ or prevalent vertebral fracture. The results were robust under a wide range of plausible assumptions. In conclusion, this study suggested, on the basis of currently available data, that denosumab was cost effective compared with no treatment for postmenopausal Belgian women with low bone mass, who were similar to the patients included in the FREEDOM trial. In addition, denosumab was found to be cost effective in the population currently reimbursed in Europe with a $T$ score $\leq-2.5$ or prevalent vertebral fracture, aged 60 years and above [31].

\subsection{Combination Treatment}

Postmenopausal women with osteoporosis were enrolled in a randomized, controlled trial. Patients were assigned to receive teriparatide $20 \mu \mathrm{g}$ daily, denosumab $60 \mathrm{mg}$ every 6 months or both. BMD was measured at $0,3,6$ and 12 months. At 12 months, posterior-anterior lumbar spine BMD increased more in the combination group $(9.1 \%$ [SD 3.9]) than in the teriparatide group (6.2\% [4.6], $P=0.0139)$ or the denosumab group (5.5\% [3.3], $P=0.0005)$. Femoral neck BMD also increased more in the combination group (4.2\% [3.0]) than in the teriparatide group (0.8\% [4.1], $P=0.0007)$ and the denosumab group (2.1\% [3.8], $P=0.0238$ ), as did total hip BMD (combination $4.9 \%$ [2.9]; teriparatide $0.7 \%$ [2.7], $P<0.0001$; denosumab $2.5 \%$ ([2.6], $P=0.0011$ ).

The authors concluded that combined teriparatide and denosumab increased BMD more than either agent alone and more than has been reported with approved therapies [32].

\subsection{Osteonecrosis of the Jaw}

A few cases of osteonecrosis of the jaw have been reported in patients with cancer or in patients with osteoporosis treated with denosumab [33-35]. Atypical femoral fractures have also been described in patients receiving denosumab [36, 37]. Whereas these cases do not provide conclusive evidence of a causal relationship between treatment with denosumab and osteonecrosis or unusual subtrochanteric fracture, other information is now required regarding the long-term safety of this potent inhibitor of bone resorption. Actually, cumulative exposure is a significant risk factor for both osteonecrosis of the jaw and atypical femoral fracture. Given the more potent antiresorptive effect of denosumab compared with oral and intravenous bisphosphonates, the incidence rates of osteonecrosis of the jaw and atypical femoral fracture might be higher with denosumab. The low numbers currently reported may, indeed, be attributable to limited clinical exposure in comparison with bisphosphonates.

\section{Cathepsin K Inhibitors}

\subsection{Mode of Action}

Cathepsin $\mathrm{K}$ is a cysteine protease of the papain family, predominantly found in osteoclasts $538^{\circ}$. Cathepsin $\mathrm{K}$ is capable of cleaving triple helical collagens in their helical domains [38]. Inhibition of bone resorption by cathepsin $\mathrm{K}$ leaves other osteoclastic functions unaffected, and some preliminary results have suggested that a cathepsin $\mathrm{K}$ inhibitor could prevent bone loss while allowing bone formation to continue [39]. Irreversible inhibitors with high potency and selectivity have been synthesized and characterized. However, these are not considered to be viable drug candidates for the treatment of osteoporosis, because of the concern that, despite their selectivity, they will, over time, react with other reactive cysteine protein species, causing toxic side effects [38]. Reversible cathepsin K covalent inhibitors have been concomitantly developed by several pharmaceutical companies (Novartis, Merck, GlaxoSmithKline, Medivir) [38]. However, most of the cathepsin $\mathrm{K}$ inhibitors that were developed for their potential effect in osteoporosis were prematurely abandoned, mainly because of safety concerns (e.g. regarding the skin). Today, odanacatib is the only remaining cathepsin $\mathrm{K}$ inhibitor that is still at a significant stage of development in osteoporosis.

\subsection{Animal Experiments}

Odanacatib is a selective and reversible inhibitor of cathepsin $\mathrm{K}$ and is currently being developed as a onceweekly treatment for osteoporosis. In a recent study, the authors evaluated the effects of odanacatib on bone turnover, BMD and bone strength in the lumbar spines of oestrogen-deficient, skeletally mature rhesus monkeys. Ovariectomized monkeys were treated in prevention mode for 21 months with either vehicle, odanacatib $6 \mathrm{mg} / \mathrm{kg}$ or odanacatib $30 \mathrm{mg} / \mathrm{kg}$ (given orally once daily) and compared with intact animals. Odanacatib treatment persistently suppressed bone resorption markers (urinary NTX [by 75-90\%] and CTX [by 40-55\%]) and serum formation markers (bone-specific alkaline phosphatase [by 30-35\%] and procollagen type I N-propeptide [by 60-70\%]) versus vehicle treatment. Treatment with odanacatib also led to dose-dependent increases in serum crosslinked C-terminal telopeptide and maintained oestrogen deficiency-elevated tartrate-resistant acid phosphatase levels, supporting the distinct mechanism of cathepsin $\mathrm{K}$ 
inhibition in effectively suppressing bone resorption without reducing osteoclast numbers. Odanacatib at both doses fully prevented bone loss in lumbar vertebrae $\left(\mathrm{L}_{1}\right.$ to $\left.\mathrm{L}_{4}\right)$ in ovariectomized animals, maintaining a BMD level comparable to that in intact animals. Odanacatib dose-dependently increased $\mathrm{L}_{1}$ to $\mathrm{L}_{4} \mathrm{BMD}$ by $7 \%$ in the $6 \mathrm{mg} / \mathrm{kg}$ group $(P<0.05$ versus the vehicle-treated ovariectomized group) and $15 \%$ in the $30 \mathrm{mg} / \mathrm{kg}$ group $(P<0.05$ versus the vehicle-treated ovariectomized group) from baseline. Treatment also trended to increase bone strength, associated with a positive and highly significant correlation $(r=0.838)$ between peak load and bone mineral content (BMC) of the lumbar spine. Whereas odanacatib reduced bone turnover parameters in trabecular bone, the number of osteoclasts was either maintained or increased in the odanacatib-treated groups compared with the vehicletreated controls. Taking these observations together, the authors felt that long-term treatment with odanacatib effectively suppressed bone turnover without reducing osteoclast numbers and maintained normal biomechanical properties of the spine in ovariectomized nonhuman primates [39].

Another study evaluated the effects of odanacatib on bone mineralization density distribution (BMDD) by quantitative backscattered electron imaging in the vertebral spongiosa, distal femoral metaphysis and cortical shaft from monkeys (aged 16-23 years) treated with vehicle $(n=5)$ or odanacatib $(6 \mathrm{mg} / \mathrm{kg}: n=4$; or $30 \mathrm{mg} / \mathrm{kg}$ : $n=4)$ given orally once daily for 21 months. Dual-energy $\mathrm{X}$-ray absorptiometry was measured in a subset of distal femoral samples. In the lumbar vertebrae, there was a shift to higher mineralization in samples from the odanacatibtreated monkeys, compared with the vehicle-treated monkeys. In distal femoral metaphyseal cancellous bone, there was a clear tendency towards a dose-dependent increase in matrix mineralization, as in the spine. However, the primary and osteonal bone of the distal cortical diaphysis showed no significant change in BMDD, whereas BMD was significantly increased after treatment. In ovariectomized monkeys, this study showed that odanacatib treatment increased trabecular BMDD, consistent with its previously reported ability to reduce cancellous remodelling. Odanacatib also showed no changes in BMDD in cortical bone sites, consistent with its actions in maintaining endocortical and stimulating periosteal bone formation [40].

The effects of odanacatib on BMD, bone strength and dynamic histomorphometric analyses of the hip were further analysed in the same monkeys. The animals were treated for 21 months with vehicle, odanacatib $6 \mathrm{mg} / \mathrm{kg}$ or odanacatib $30 \mathrm{mg} / \mathrm{kg}$ (given orally once daily). Odanacatib increased femoral neck BMD by 11 and $15 \%(P<0.07)$ and ultimate load by $25 \%(P<0.05)$ and $30 \%(P<0.01)$ versus vehicle. Treatment-related increases in ultimate load positively correlated with the increased femoral neck BMD, BMC and cortical thickness. Histomorphometry of the femoral neck and proximal femur revealed that odanacatib reduced the trabecular and intracortical bone formation rates but did not affect the long-term endocortical bone formation rate. Moreover, the $30 \mathrm{mg} / \mathrm{kg}$ odanacatib dose stimulated the long-term femoral neck and proximal femur periosteal bone formation rates by 3.5 - and 6-fold, respectively, versus vehicle. Osteoclast surfaces were either unaffected or trended higher ( $\sim 2$-fold) in endocortical and trabecular surfaces in the odanacatib group. Lastly, odanacatib increased the cortical thickness of the femoral neck by $21 \%(P=0.08)$ and the proximal femur by $19 \%(P<0.05)$ versus vehicle after 21 months of treatment. Together, both doses of odanacatib increased bone mass and improved bone strength at the hip. Unlike conventional antiresorptives, odanacatib displayed site-specific effects on trabecular versus cortical bone formation. The drug provided marked increases in periosteal bone formation and cortical thickness in ovariectomized monkeys [41].

\subsection{Phase 1 Studies}

In two double-blind, randomized, placebo-controlled phase 1 studies, postmenopausal female subjects received odanacatib once weekly for 3 weeks or once daily for 21 days. BTMs, safety monitoring and plasma odanacatib concentrations were assessed. These studies showed odanacatib to be well tolerated. Pharmacokinetic analysis revealed a long half-life $\left(\mathrm{t}_{1} / 2\right.$; 66-93 h) consistent with once-weekly dosing. Pronounced reductions in CTX (approximately $62 \%$ ) and NTX normalized to creatinine [NTX/Cr] (approximately $62 \%$ ) at trough $(\mathrm{C}(168 \mathrm{~h}))$ were seen following weekly administration. Robust reductions in CTX (up to $81 \%$ ) and NTX/Cr (up to $81 \%$ ) were seen following daily administration. Odanacatib exhibits robust and sustained suppression of bone resorption biomarkers (CTX and NTX/Cr) at weekly doses $\geq 25 \mathrm{mg}$ and daily doses $\geq 2.5 \mathrm{mg}$ [42].

\subsection{Phase 2 Studies}

A 1-year dose-finding trial with a 1-year extension on the same treatment assignment was performed in postmenopausal women with low BMD to evaluate the safety and efficacy of weekly oral doses of placebo or odanacatib 3, 10,25 or $50 \mathrm{mg}$ on BMD and biomarkers of skeletal remodelling. Women with BMD $T$ scores of -2.0 or less but not less than -3.5 at the lumbar spine or femoral sites were randomly assigned to receive placebo or one of four doses of odanacatib; all received vitamin $\mathrm{D}$, with calcium supplementation as needed. The primary endpoint was the percentage change from the baseline lumbar spine BMD. 
Other endpoints included the percentage change in BMD at hip and forearm sites, as well as changes in biomarkers of skeletal remodelling. Twenty-four months of treatment produced progressive dose-related increases in BMD. With the $50 \mathrm{mg}$ dose of odanacatib, lumbar spine and total hip BMD increased by 5.5 and $3.2 \%$, respectively, whereas $\mathrm{BMD}$ at these sites was essentially unchanged with placebo $(-0.2$ and $-0.9 \%)$. Biochemical BTMs exhibited doserelated changes. The safety and tolerability of odanacatib generally were similar to those of placebo, with no doserelated trends in any adverse experiences. In summary, 2 years of weekly odanacatib treatment was generally well tolerated and increased lumbar spine and total hip BMD in a dose-related manner in postmenopausal women with low BMD [43].

An extension of this study was recently published. Continued treatment with odanacatib $50 \mathrm{mg}$ for 3 years produced significant increases from baseline and from year 2 in BMD at the spine (7.9 and $2.3 \%$, respectively) and total hip (5.8 and $2.4 \%$, respectively). Urine NTX remained suppressed at year $3(-50.5 \%)$, but bone-specific alkaline phosphatase was relatively unchanged from baseline. Treatment discontinuation resulted in bone loss at all sites, but BMD remained at or above baseline. After odanacatib discontinuation at month 24, BTMs increased transiently above baseline, but this increase largely resolved by month 36 . There were similar overall adverse event rates in both treatment groups [44]. For years 4 and 5, women who had received placebo or odanacatib $3 \mathrm{mg}$ in years 1 and 2 and placebo in year 3 received odanacatib $50 \mathrm{mg}$; others continued their year 3 treatments. The endpoints included lumbar spine BMD (the primary endpoint) and hip, one third radius and total body BMD; markers of bone metabolism; and safety. Women in the year 4-5 extension receiving placebo $(n=41)$ or odanacatib $50 \mathrm{mg}$ ( $n=100$ ) had similar baseline characteristics. For women who received odanacatib (10-50 mg) for 5 years, spine and hip BMD increased over time. With odanacatib $50 \mathrm{mg}$ continually for 5 years $(n=13)$, the mean lumbar spine BMD percentage change from baseline was $11.9 \%(95 \%$ CI 7.2-16.5) versus $-0.4 \%$ ( -3.1 to 2.3 ) for women who were switched from odanacatib $50 \mathrm{mg}$ to placebo after 2 years $(n=14)$. In pooled results for women receiving continuous odanacatib (10-50 mg, $n=26-29)$, the year 5 geometric mean percentage changes from baseline in the bone resorption markers NTX/Cr and CTX were approximately $-55 \%$, but the values for the bone formation markers bone-specific alkaline phosphatase and procollagen type I N-propeptide were near baseline. In women switched from odanacatib $10-50 \mathrm{mg}$ to placebo after 2 years $(n=25)$, BTM values were near baseline. In summary, women receiving combinations of odanacatib (10-50 mg) for 5 years had gains in spine and hip BMD and showed larger reductions in bone resorption than bone formation markers. Discontinuation of odanacatib resulted in reversal of treatment effects. Treatment with odanacatib for up to 5 years was generally well tolerated [45].

In a randomized, double-blind, placebo-controlled, 24-month study, 243 postmenopausal women $\geq 60$ years of age with low BMD at the total hip, femoral neck or trochanter ( $T$ score $\leq-2.5$ but $>-3.5$ without prior fracture or $\geq-1.5$ but $>-3.5$ with prior fracture) on alendronate for $\geq 3$ years received odanacatib $50 \mathrm{mg}$ or placebo weekly.

In the odanacatib group, BMD changes from baseline at the femoral neck, trochanter, total hip and lumbar spine at 24 months $(1.7,1.8,0.8$ and $2.3 \%$, respectively) were significantly different from those in the placebo group. Odanacatib significantly decreased the urinary $\mathrm{NTX} / \mathrm{Cr}$ ratio and significantly increased serum procollagen type I N-propeptide compared with placebo. Serum CTX was unexpectedly increased with odanacatib treatment. The safety profile appeared similar between groups [46].

A double-blind, 2-year trial randomized 214 postmenopausal women with low BMD to receive odanacatib $50 \mathrm{mg}$ or placebo weekly. Bone strength estimated by finite element analysis at the hip was significantly increased when compared with placebo at 6 months. At the cortical envelop of the femoral neck, the BMC, thickness, volume and cross-sectional area were also increased from baseline with odanacatib versus placebo at up to 2 years [47].

The efficacy and safety of oral placebo or odanacatib 10 , 25 or $50 \mathrm{mg}$ once weekly for 52 weeks were evaluated in a double-blind, randomized, multicentre study in Japanese female and male patients with osteoporosis. The primary efficacy endpoint was the percentage change from baseline to week 52 in the lumbar spine BMD. The secondary endpoints included the percentage changes in total hip, femoral neck and trochanter BMD and in bone biomarkers after treatment for 52 weeks. In this study, 286 patients (94\% female; mean age 68.2 [SD 7.1] years) were included in the analysis. The least-squares mean percentage changes from baseline to week 52 in the groups receiving placebo, $10 \mathrm{mg}$, $25 \mathrm{mg}$ and $50 \mathrm{mg}$ of odanacatib for lumbar spine $\left(\mathrm{L}_{1}\right.$ to $\left.\mathrm{L}_{4}\right)$ BMD were 0.5, 4.1, 5.7 and 5.9\%, respectively, and for total hip BMD they were $0.4,1.3,1.8$ and $2.7 \%$, respectively. The changes in femoral neck and trochanter BMD were similar to those at the total hip. BTMs were reduced in a dose-dependent manner. However, the effects of odanacatib on bone formation markers were lesser than the effects on bone resorption markers. Tolerability and safety profiles were similar among all treatment groups, with no dose-related trends in any adverse events. This suggests that weekly odanacatib treatment for 52 weeks increases BMD at the lumbar spine and at all hip sites in a dose-dependent manner and is well tolerated in Japanese patients with osteoporosis [48]. 


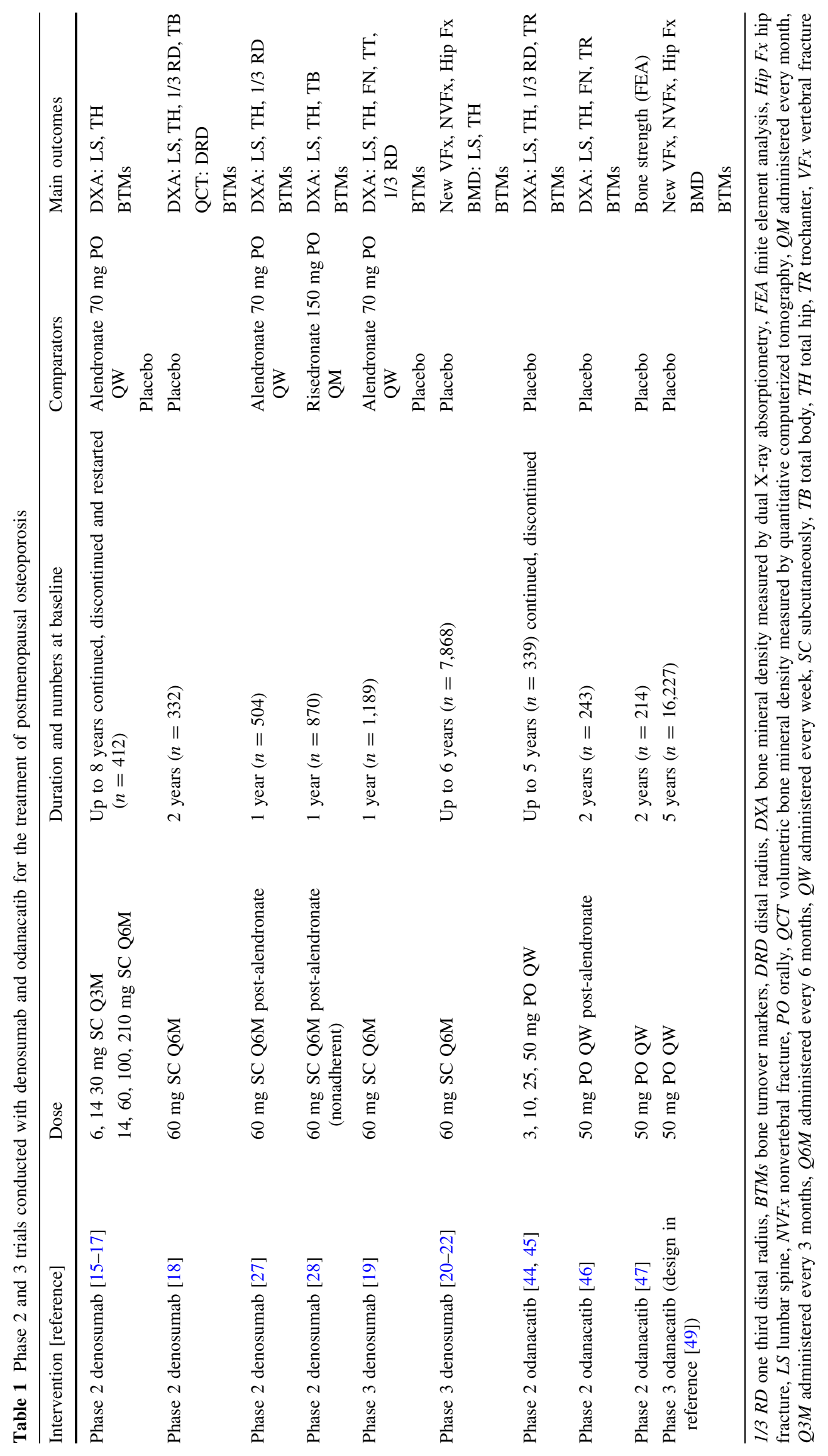




\subsection{Phase 3 Studies}

A randomized, double-blind, phase 3 trial, designed to examine fracture reduction and safety, enrolled 16,227 postmenopausal osteoporotic women to receive odanacatib $50 \mathrm{mg}$ or placebo once weekly. The primary endpoints included morphometric vertebral fracture, nonvertebral fracture and hip fracture. A pre-planned interim analysis demonstrated anti-fracture efficacy and a favourable benefit/risk profile. Because of safety findings, the trial is currently being extended for a minimal total period of observation of 5 years. The results are expected to become available during the fall of 2014 [49].

\section{Conclusion}

For 25 years, inhibitors of bone resorption and, more specifically, bisphosphonates and selective oestrogen receptor modulators have considerably modified the armamentarium of osteoporosis. However, the lack of efficacy of selective oestrogen receptor modulators on nonvertebral and hip fractures in the general population, as well as questions raised about the long-term skeletal safety of bisphosphonates, together with poor long-term adherence, have prompted the development of new inhibitors of bone resorption (Table 1). Denosumab has shown efficacy in vertebral, nonvertebral and hip fractures. This 6-monthly subcutaneous formulation might significantly influence compliance and persistence with therapy. It is also the only anti-osteoporosis treatment that can be considered in patients with renal insufficiency [50]. Additional results regarding long-term skeletal safety (i.e. osteonecrosis of the jaw and atypical diaphyseal femoral fracture) are needed.

Odanacatib is a promising new approach to the inhibition of osteoclastic resorption, with the potential to uncouple bone formation from bone resorption. Results regarding its anti-fracture efficacy are expected to become available during the fall of 2014 [51].

These new inhibitors of bone resorption, given either subcutaneously every 6 months or orally every week, have the potential advantage of an improvement in long-term adherence, mainly because of the lack of constraints related to their administration. For odanacatib, the uncoupling between bone formation and bone resorption might provide an additional clinical benefit, compared with pure antiresorptive agents, and could also preclude the development of long-term skeletal adverse reactions, including osteonecrosis of the jaw and atypical femoral fracture, which have been reported with bisphosphonates and denosumab.

\footnotetext{
Acknowledgments Jean-Yves Reginster:

Consulting fees or paid advisory boards: Servier, Novartis, Negma, Lilly, Wyeth, Amgen, GlaxoSmithKline, Roche, Merckle, Nycomed-
}

Takeda, NPS, IBSA-Genevrier, Theramex, UCB, Asahi Kasei, Endocyte.

Lecture fees when speaking at the invitation of a commercial sponsor: Merck Sharp and Dohme, Lilly, Rottapharm, IBSA, Genevrier, Novartis, Servier, Roche, GlaxoSmithKline, Merckle, Teijin, Teva, Analis, Theramex, Nycomed, NovoNordisk, Ebewee Pharma, Zodiac, Danone, Will Pharma, Amgen.

Grant support from industry: Bristol Myers Squibb, Merck Sharp \& Dohme, Rottapharm, Teva, Roche, Amgen, Lilly, Novartis, GlaxoSmithKline, Servier, Pfizer, Theramex, Danone, Organon, Therabel, Boehringer, Chiltern, Galapagos.

Olivier Bruyere:

Consulting fees or paid advisory boards: Bayer, Genevrier, IBSA, Rottapharm, Servier, SMB.

Lecture fees when speaking at the invitation of a commercial sponsor: IBSA, Merck Sharp \& Dohme, Novartis, Pfizer, Rottapharm, Servier, Theramex.

Grant support from industry: IBSA, Merck Sharp \& Dohme, Novartis, Nutraveris, Pfizer, Rottapharm, Servier, Theramex.

Audrey Neuprez:

Grant support from industry: Amgen, Servier.

Charlotte Beaudart has no conflict of interest.

Marie-Paule Lecart has no conflict of interest.

Nathalie Sarlet has no conflict of interest.

Delphine Bernard has no conflict of interest.

Stephan Disteche has no conflict of interest.

Open Access This article is distributed under the terms of the Creative Commons Attribution Noncommercial License which permits any noncommercial use, distribution, and reproduction in any medium, provided the original author(s) and the source are credited.

\section{References}

1. Consensus Development Conference. Diagnosis, prophylaxis, and treatment of osteoporosis. Am J Med. 1993;94:646-50.

2. Kanis JA, McCloskey EV, Johansson H, Cooper C, Rizzoli R, Reginster JY, on behalf of the Scientific Advisory Board of the European Society for Clinical and Economic Aspects of Osteoporosis and Osteoarthritis (ESCEO) and the Committee of Scientific Advisors of the International Osteoporosis Foundation (IOF). European guidance for the diagnosis and management of osteoporosis in postmenopausal women. Osteoporos Int. 2013;24:23-57.

3. Wysowski DK, Greene P. Trends in osteoporosis treatment with oral and intravenous bisphosphonates in the United States, 2002-2012. Bone. 2013;57:423-8.

4. Suresh E, Pazianas M, Abrahamsen B. Safety issues with bisphosphonate therapy for osteoporosis. Rheumatology. 2014;53:19-31.

5. Reginster JY, Pelousse F, Bruyère $O$. Safety concerns with the long-term management of osteoporosis. Expert Opin Durg Saf. 2013;12:507-22.

6. Rabenda V, Mertens R, Fabri V, Vanoverloop J, Sumkay F, Vannecke C, Deswaef A, Verpooten GA, Reginster JY. Adherence to bisphosphonates therapy and hip fracture risk in osteoporotic women. Osteoporos Int. 2008;19:811-8.

7. Hiligsmann $M$, Rabenda $V$, Bruyère $O$, Reginster JY. The clinical and economic burden of non-adherence with oral bisphosphonates in osteoporotic patients. Health Policy. 2010;96:170-7.

8. Delmas PD, Genant HK, Crans CG, Stock JL, Wong M, Siris E, Adachi JD. Severity of prevalent vertebral fractures and the risk of subsequent vertebral and non-vertebral fractures: results from the MORE trial. Bone. 2003;33:522-32. 
9. Kaufman JM, Palacios S, Silverman S, Sutradhar S, Chines A. An evaluation of the fracture risk assessment tool $\left(\right.$ FRAX $\left.^{\circledR}\right)$ as an indicator of treatment efficacy: the effects of bazedoxifene and raloxifene on vertebral, nonvertebral, and all clinical fractures as a function of baseline fracture risk assessed by FRAX $^{\circledR}$ ). Osteoporos Int. 2013;24:2561-9.

10. De Villiers TJ, Chines AA, Palacios S, Lips P, Sawicki AZ, Levine A, Codreanu C, Kelepouris N, Brown JP. Safety and tolerability of bazedoxifene in postmenopausal women with osteoporosis: results of a 5-year, randomized, placebo-controlled phase 3 trial. Osteoporos Int. 2011;22:567-76.

11. Kanis JA, Reginster JY, Kaufman JM, Ringe JD, Adachi JD, Hiligsmann M, Rizzoli R, Cooper C. A reappraisal of generic bisphosphonates in osteoporosis. Osteoporos Int. 2012;23:213-21.

12. Hofbauer LC, Schoppet M. Clinical implications of the osteoprotegerin/RANKL/RANK system for bone and vascular disease. JAMA. 2004;292:490-5.

13. Abdallah BM, Stilgren LS, Nissen N, Kassem M, Jorgensen HR, Abrahamsen B. Increased RANKL/OPG mRNA ratio in iliac bone biopsies from women with hip fractures. Calcif Tissue Int. 2005;76:90-7.

14. Bekker PJ, Holloway DL, Rasmussen AS, Murphy R, Martin SW, Leese PT, Holmes GB, Dunstan CR, DePaoli AM. A single-dose placebo-controlled study of AMG 162, a fully human monoclonal antibody to RANKL, in postmenopausal women. J Bone Miner Res. 2004;19:1059-66.

15. McClung MR, Lewiecki EM, Cohen SB, Bolognese MA, Woodson GC, Moffett AH, Peacock M, Miller PD, Lederman SN, Chesnut CH, Lain D, Kivitz AJ, Holloway DL, Zhang C, Peterson MC, Bekker PJ, AMG 162 Bone Loss Study Group. Denosumab in postmenopausal women with low bone mineral density. N Engl J Med. 2006;354:821-31.

16. McClung MR, Lewieck EM, Geller ML, Bolognese MA, Peacock M, Weinstein RL, Ding B, Rockarand E, Wagman RB, Miller PD. Effect of denosumab on bone mineral density and biochemical markers of bone turnover: 8 -year results of a phase 2 clinical trial. Osteoporos Int. 2013;24:227-35.

17. Miller PD, Bolognese MA, Lewiecki EM, McCling MR, Ding B, Austin M, Liu Y, San Martin J, Ang Bone Loss Study Group. Effect of denosumab on bone density and turnover in postmenopausal women with low bone mass after long-term continued, discontinued, and restarting of therapy: a randomized blinded phase 2 clinical trial. Bone. 2008;43:222-9.

18. Bone HG, Bolognese MA, Yuen CK, Kendler DL, Wang H, Liu Y, San Martin J. Effects of denosumab on bone mineral density and bone turnover in postmenopausal women. J Clin Endocrinol Metab. 2008;93:2149-67.

19. Brown JP, Prince RL, Deal C, Recker RR, Kiel DP, de Gregorio LH, Hadji P, Hofbauer LC, Alvaro-Gracia JM, Wang H, Austin M, Wagman RB, Newmark R, Libanati C, San Martin J, Bone HG. Comparison of the effect of denosumab and alendronate on bone mineral density and biochemical markers of bone turnover in postmenopausal women with low bone mass: a randomized, blinded, phase 3 trial. J Bone Miner Res. 2009;14:1-34.

20. Cummings SR, SanMartin J, McClung MR, Siris ES, Eastell R, Reid IR, Delmas P, Zoog HB, Austin M, Wang A, Kutilek S, Adami S, Zanchetta J, Libanati C, Siddhanti S, Christiansen C, FREEDOM Trial. Denosumab for prevention of fractures in postmenopausal women with osteoporosis. J Bone Miner Res. 2010;361:756-65.

21. Papapoulos S, Chapurlat R, Libanati C, Brandi ML, Brown JP, Czewinski E, Krieg MA, Man Z, Mellström D, Radominski SC, Reginster JY, Resch H, Roman Ivorra JA, Roux C, Vittinghoff E, Austin M, Daizadeh N, Bradley MN, Grauer A, Cummings SR, Bone HG. Five years of denosumab exposure in women with postmenopausal osteoporosis: results from the first two years of the FREEDOM extension. J Bone Miner Res. 2012;27:694-701.

22. Bone HG, Chapurlat R, Brandi ML, Brown JP, Czerwinski E, Krieg MA, Mellström D, Radominski SC, Reginster JY, Resch H, Ivorra JA, Roux C, Vittinghoff E, Daizadeh NS, Wang A, Bradley MN, Franchimont N, Geller ML, Wagman RB, Cummings SR, Papapoulos S. The effect of three or six years denosumab exposure in women with postmenopausal osteoporosis: results from the FREEDOM extension. J Clin Endocrinol Meb. 2013;98:4483-92.

23. Brown JP, Roux C, Törring O, Ho PR, BeckJensen JE, Gilschrist N, Recknor C, Austin M, Wang A, Gr'auer A, Wagman RB. Discontinuation of denosumab and associated fracture incidence: analysis from the fracture reduction evaluation of denosumab in osteoporosis every 6 months (FREEDOM) trial. J Bone Miner Res. 2013;28:746-52.

24. Eastell R, Christiansen C, Grauer A, Kutilek S, Libanati C, McClung MR, Reid IR, Resch H, Siris E, Uebelhart D, Wang A, Weryha G, Cummings SR. Effects of denosumab on bone turnover markers in postmenopausal osteoporosis. J Bone Miner Res. 2011;26:530-7.

25. McCloskey EV, Johansson H, Oden A, Austin M, Siris E, Wang A, Lewiecki EM, Lorenc R, Libanati C, Kanis JA. Denosumab reduces the risk of osteoporotic fractures in postmenopausal women, particularly in those with moderate to high fracture risk as assessed with FRAX. J Bone Miner Res. 2012;27:1480-6.

26. McClung MR, Boonen S, Törring O, Roux C, Rizzoli R, Bone HG, Benhamou CL, Lems WF, Minisola S, Hales J, Hoeck HC, Eastell R, Wang A, Siddhanti S, Cummings SR. Effect of denosumab treatment on the risk of fractures in subgroups of women with postmenopausal osteoporosis. J Bone Miner Res. 2012;27:211-8.

27. Kendler DL, Roux C, Benhamou CL, Brown JP, Lillestol M, Siddhanti S, Man HS, San Martin J, Bone HG. Effects of denosumab on bone mineral density and bone turnover in postmenopausal women transitioning from alendronate therapy. J Bone Miner Res. 2010;25:72-81.

28. Roux C, Hofbauer LC, Ho PR, Wark JD, Zillikens MC, Fahrleitner-Pammer A, Hawkins F, Micaelo M, Minisola S, Papaioannou N, Stone M, Ferreira I, Siddhanti S, Wagman RB, Brown JP. Denosumab compared with risedronate in postmenopausal women suboptimally adherent to alendronate therapy: efficacy and safety results from a randomized open-label study. Bone. 2014;58:48-54.

29. Reid IR, Miller PD, Brown JP, Kendler DL, Fahrleitner-Pammer A, Valter I, Maasalu K, Bolognese MA, Woodson G, Bone H, Ding B, Wagman RB, San Martin J, Ominsky MS, Dempster DW, Denosumab Phase 3 Bone Histology Study Group. Effects of denosumab on bone histomorphometry: the FREEDOM and STAND studies. J Bone Miner Res. 2010;25:2256-65.

30. Kendler DL, McClung MR, Freemantle N, Lillestol M, Moffett AH, Borenstein J, Satram-Hoang S, Yang YC, Kaur P, Macarios D, Siddhanti S, on behalf of the DAPS Investigators. Adherence, preference, and satisfaction of postmenopausal women taking denosumab or alendronate. Osteoporos Int. 2011;22:1725-35.

31. Hiligsmann M, Reginster JY. Potential cost-effectiveness of denosumab for the treatment of postmenopausal osteoporotic women. Bone. 2010;47:34-40.

32. Tsai JN, Uihlein AV, Lee H, Kumbhani R, Siwila-Sackman E, McKay EA, Burnett-Bowie SA, Neer RM, Leder BZ. Teriparatide and denosumab, alone or combined, in women with postmenopausal osteoporosis: the DATA Study randomized trial. Lancet. 2013;382:50-6.

33. Sivolella S, Lumachi F, Stellini E, Favero L. Denosumab and antiangiogenetic drug-related osteonecrosis of the jaw: an uncommon but potentially severe disease. Anticarcer Res. 2013;33:1793-7. 
34. Otto S, Baumann S, Ehrenfeld M, Pautke C. Successful surgical management of osteonecrosis of the jaw due to RANK-ligand inhibitor treatment using fluorescence guided bone resection. J Craniomaxillofac Surg. 2013;41:694-8.

35. Neuprez A, Coste S, Rompen E, Crielaard JM, Reginster JY. Osteonecrosis of the jaw in a male osteoporotic patient treated with denosumab. Osteoporos Int. 2014;25:393-5.

36. Drampalos E, Skarpas G, Barbounakis N, Michos I. Atypical femoral fractures bilaterally in a patient receiving denosumab. Acta Orthop. 2013;85:3-5.

37. Paparodis R, Buehring B, Pelley EM, Binkley N. A case of an unusual subtrochanteric fracture in a patient receiving denosumab. Endocr Pract. 2013;19:64-8.

38. Grabowskal U, Chambers TJ, Shiroo M. Recent developments in cathepsin K inhibitor design. Curr Opin Drug Discov Devel. 2005;8:619-30.

39. Masarachia PJ, Pennypacker BL, Pickarski M, Scott KR, Wesolowski GA, Smith SY, Samadfam R, Goetzmann JE, Scott BB, Kimmel DB, Duong Le T. Odanacatib reduces bone turnover and increases bone mass in the lumbar spine of skeletally mature ovariectomized rhesus monkeys. J Bone Miner Res. 2012;27:509-23.

40. Fratzl-Zelman N, Roschger P, Fisher JE, Duong LT, Klaushofer $\mathrm{K}$. Effects of odanacatib on bone mineralization density distribution in thoracic spine and femora of ovariectomized adult rhesus monkeys: a quantitative backscattered electron imaging study. Calc Tissue Int. 2013;92:261-9.

41. Cusick T, Chen CM, Pennypacker BL, Pickarski M, Kimmel DB, Scott BB, Dunong Le T. Odanacatib treatment increases hip bone mass and cortical thickness by preserving endocortical bone formation and stimulating periosteal bone formation in the ovariectomized adult rhesus monkey. J Bone Miner Res. 2012;27:524-37.

42. Stoch SA, Zajic S, Stone J, Miller DL, Van Dyck K, Gutierrez MJ, De Decker M, Liu L, Liu Q, Scott BB, Panebianco D, Jin B, Duong LT, Gottesdiener K, Wagner JA. Effect of the cathepsin K inhibitor odanacatib on bone resorption biomarkers in healthy postmenopausal women: two double-blind, randomized, placebocontrolled phase I studies. Clin Pharmacol Ther. 2009;86: $175-82$.

43. Bone HG, McClung MR, Roux C, Recker RR, Eisman JA, Verbruggen N, Hustad CM, DaSilva C, Santora AC, Ince BA.
Odanacatib, a cathepsin-K inhibitor for osteoporosis: a two-year study in postmenopausal women with low bone density. J Bone Miner Res. 2010;25:937-47.

44. Eisman JA, Bone HG, Hosking DJ, McClung MR, Reid IR, Rizzoli R, Resch H, Verbruggen N, Hustad CM, Dasilva C, Petrovic R, Santora AC, Avery Ince B, Lombardi A. Odanacatib in the treatment of postmenopausal women with low bone mineral density: three-year continued therapy and resolution of effect. J Bone Miner Res. 2011;26:242-51.

45. Langdahl B, Binkley N, Bone H, Gilchrist N, Resch H, Rodriguez Portales J, Denker A, Lombardi A, Le Bailly De Tilleghem C, DaSilva C, Rosenberg E, Leung A. Odanacatib in the treatment of postmenopausal women with low bone mineral density: five years of continued therapy in a phase 2 study. J Bone Miner Res. 2012;27:2251-8.

46. Bonnick S, De Villiers T, Odio A, Palacios S, Chapurlat R, Dasilva C, Scott BB, Le Baily De Tilleghem C, Leung AT, Gurner D. Effects of odanacatib on BMD and safety in the treatment of osteoporosis in postmenopausal women previously treated with alendronate: a randomized placebo-controlled trial. J Clin Endocrinol Metab. 2013;98:4727-35.

47. Brixen K, Chapurlat R, Cheung AM, Keaveny TM, Fuerst T, Engelke K, Recker R, Dardzinski B, Verbruggen N, Ather S, Rosenberg E, de Papp AE. Bone density, turnover, and estimated strength in postmenopausal women treated with odanacatib: a randomized trial. J Clin Endocrinol Metab. 2013;98:571-80.

48. Nakamura T, Shiraki M, Fukunaga M, Tomomitsu T, Santora AC, Tsai R, Fujimoto G, Nakagomi M, Tsubouchi H, Rosenberg E, Uchida S. Effect of the cathepsin $\mathrm{K}$ inhibitor odanacatib administered once weekly on bone mineral density in Japanese patients with osteoporosis-a double-blind, randomized, dosefinding study. Osteoporos Int. 2014;25:367-76.

49. Papapoulos S, Bone HB, Dempster DW, Eisman J, Greenspan S, McClung M, Nakamura T, Shih J, Leung A, Santora A, Verbruggen N, Lombardi A. Phase 3 fracture trial of odanacatib for osteoporosis. Baseline characteristics and study design. Arthritis Rheum. 2013;65 Supp:S515-6.

50. Silverman S, Christiansen C. Individualizing osteoporosis therapy. Osteoporos Int. 2012;23:797-809.

51. Yasuda Y, Kaleta J, Bromme D. The role of cathepsins in osteoporosis and arthritis: rationale for the design of new therapeutics. Adv Drug Deliv Rev. 2005;57:973-93. 